\title{
OPEN STRATEGIZING E INCERTEZA PERCEBIDA: O ENFOQUE ESTRATÉGICO E CONTINGENCIAL NO ENFRENTAMENTO À CRISE CAUSADA PELA PANDEMIA DO COVID-19 ${ }^{1}$
}

\author{
Rosalia Aldraci Barbosa Lavarda ${ }^{2}$ \\ Bárbara Zandomenico Perito ${ }^{3}$ \\ Lucas Miguel Gnigler ${ }^{4}$ \\ Robson Vander Canarin da Rocha ${ }^{5}$
}

http://dx.doi.org/10.1590/1413-2311.311.104094

\begin{abstract}
RESUMO
O objetivo desta pesquisa foi compreender como ocorre o processo de open strategizing frente à incerteza percebida pela turbulência do ambiente causada pela pandemia do COVID-19. Nesse contexto de crise, a forma como ocorre a abertura da estratégia é impactada pelas ações corretivas imediatamente necessárias. Foi realizado um estudo de caso em uma organização que presta serviço não essencial e sofreu impactos diretos, precisando alterar repentinamente suas estratégias, operando com limitações e seguindo as recomendações dos decretos governamentais. A coleta de dados foi por meio de entrevistas, observação direta e análise de documentos. A partir da análise de narrativa e comparação de padrões teóricos/empíricos dos dados, encontramos que o processo de open strategizing ocorre de forma integradora; as decisões ocorrem no sentido middle-up-down, integrando pessoas, estrutura e estratégia de maneira não linear ou estruturada, com adoção de algumas práticas de inclusão e transparência da informação no momento em que o fenômeno estava se desenvolvendo em larga escala, em nível mundial. A pandemia segue em evolução, e as incertezas predominam no contexto global e local desafiando a tomada de decisão enquanto esta pesquisa acontece.

\footnotetext{
${ }^{1}$ Recebido em 18/6/2020, aceito em 9/2/2021.

2 Universidade Federal de Santa Catarina - Programa de Pós-graduação em Administração; Florianópolis (SC) Brasil; http://orcid.org/0000-0002-1093-4486; rosalia.lavarda@ufsc.br.

3 Universidade Federal de Santa Catarina - Programa de Pós-graduação em Administração; Florianópolis (SC) Brasil; http://orcid.org/0000-0003-0980-2301; bibazp@gmail.com.

4 Universidade Federal de Santa Catarina - Programa de Pós-graduação em Administração; Florianópolis (SC) Brasil; http://orcid.org/0000-0003-1589-9090; contato@lucasmiguel.com.

5 Universidade Federal de Santa Catarina - Programa de Pós-graduação em Administração; Florianópolis (SC) Brasil; http://orcid.org/0000-0002-3734-6019 ; robsonvcrocha@ gmail.com.
}

(c) (1) (9) REAd | Porto Alegre - Vol. 27 - N. 1 - Janeiro / Abril 2021 - p. 1-34. 
Palavras-chave: Open Strategizing. Incerteza Percebida. Ambiente. Pandemia. COVID-19.

\section{OPEN STRATEGIZING AND PERCEIVED UNCERTAINTY: THE STRATEGIC AND CONTINGENTIAL APPROACH IN ADDRESSING THE CRISIS CAUSED BY \\ THE COVID-19 PANDEMIC}

The goal of this research was to understand how the process of open strategizing occurs facing the uncertainty perceived by the environment turbulence caused by the pandemic of COVID19. In this context of crisis, the way in which the strategy is opened is impacted by the immediately necessary corrective actions. A case study was carried out in an organization that provides non-essential services and that suffered direct impacts, needing to change its strategies suddenly, operating with limitations and following the recommendations of government decrees. Data collection was carried out through interviews, participant observation and document analysis. From the narrative analysis and comparison of theoretical/empirical patterns of data, we found that open strategizing process occurs in an integrative way, the decisions occur in the middle-up-down sense, integrating people, structure and strategy in a non-linear or structured way, with the adoption of some practices of inclusion and transparency of information at the time when the phenomenon was developing on a large scale, worldwide. The pandemic continues to evolve and uncertainties still predominate in the global, national and local context, challenging decision making while this research is taking place.

Keywords: Open Strategizing. Uncertainty. Environment. Pandemic. COVID-19.

\section{ESTRATEGIA ABIERTA E INCERTIDUMBRE PERCIBIDA: EL ENFOQUE ESTRATÉGICO Y CONTINGENCIAL PARA ENFRENTAR LA CRISIS PROVOCADA POR LA PANDEMIA DEL COVID-19}

El objetivo de esta investigación fue comprender cómo se produce el proceso de apertura de la estrategia frente a la incertidumbre percibida por la turbulencia causada por la pandemia de COVID-19. En este contexto de crisis, la forma de apertura de la estrategia se ve impactada por las acciones correctivas inmediatamente necesarias. Se realizó un estudio de caso en una organización de servicios no esenciales, que sufrió impactos directos, necesitando cambiar sus estrategias repentinamente, operando con limitaciones y siguiendo las recomendaciones de los decretos gubernamentales. La recolección de datos se realizó con entrevistas, observación y análisis de documentos. A partir del análisis de las narrativas, encontramos que el proceso de apertura de la estrategia ocurre de manera integradora, las decisiones ocurren en el sentido middle-up-down, integrando personas, estructura y estrategia de manera no lineal o estructurada, con la adopción de algunas prácticas de inclusión y transparencia de la información en el momento en que el fenómeno se desarrollaba a gran escala en todo el mundo. La pandemia continúa evolucionando y las incertidumbres aún predominan en el contexto global, nacional y local, desafiando la toma de decisiones, mientras se lleva a cabo esta investigación.

Palabras-clave: Estrategia abierta. Incertidumbre. Ambiente. Pandemia. COVID-19. 


\section{INTRODUÇÃO}

A abertura da estratégia coincide com a necessidade de novas posturas para explicar os fenômenos que tratam das relações das pessoas com a estratégia nas organizações (MACK; SZULANSKI, 2017; BURGELMAN et al., 2018; WHITTINGTON, 2019), assim como de novas abordagens para tratar enfoques do processo estratégico frente às adversidades e grandes desafios do ambiente (JARZABKOWSKI et al., 2019). A open strategizing, a partir da perspectiva da estratégia como prática e em decorrência da evolução dos conceitos de estratégia (ABDALLA; CONEJERO; OLIVEIRA, 2019), aborda elementos como a inclusão das pessoas e a transparência da informação (WHITTINGTON; CAILLUET; YAKIS-DOUGLAS, 2011), que parecem basilares para explicar a implementação da estratégia frente às contingências.

Esses fatores de abertura da estratégia caracterizam a adoção de uma postura que pode ser consciente e deliberada (MINTZBERG; WATERS, 1985; ANDERSEN, 2004) pela alta gestão para responder às complexidades e incertezas contingenciais (DUNCAN, 1972). Esta forma de abertura da estratégia pode ser também autônoma e emergente, proveniente das idiossincrasias da organização, do nível no qual a rotina operacional está estabelecida (ANDERSEN, 2000). Uma combinação dessas duas possibilidades pode gerar valor adicional para a organização, e essa seria uma forma integradora de promover a abertura da estratégia para enfrentar as contingências do ambiente.

Estratégia e ambiente são elementos indissociáveis, pois a eficiência organizacional resulta do ajuste interno das características da organização, com os fatores de contingência (BURNS; STALKER, 1961; LAWRENCE; LORSCH, 1967; DONALDSON, 2001). Neste estudo, a estratégia a partir da perspectiva da prática (WHITTINGTON, 1996, 2019) está sujeita às características (turbulência) do ambiente externo, que pode ser entendido por pelo menos duas dimensões: (i) dinamismo e (ii) complexidade (DUNCAN, 1972; MINTZBERG; AHLSTRAND; LAMPEL, 2010). O ambiente externo, suas dinâmicas e complexidades geram novas incertezas em todos os indivíduos e relações que compõem uma organização. Diante disso, a inclusão das pessoas e a transparência da informação se tornam fundamentais para entender e atender às necessidades tanto da empresa quanto das pessoas.

A crise causada pela pandemia do COVID-19, declarada em 11 de março de 2020 pela Organização Mundial da Saúde (OMS) como o surto causado pelo novo coronavírus (SARSCoV-2, COVID-19), desafia comportamentos, instituições e governos; diversas são as perspectivas pelas quais essa adversidade pode ser focalizada. O nosso enfoque é o nível micro- 
organizacional, no qual as organizações precisam se reestruturar, se preparar e atuar com novos objetivos e práticas para responder a essa situação de crise.

Diante desse contexto, delineamos a questão de pesquisa: como ocorre o processo de open strategizing frente à incerteza percebida pela turbulência do ambiente causada pela pandemia do COVID-19? As perspectivas da teoria da contingência apontam para o grau de influência que uma situação de crise pode representar para uma organização. Assim, a abertura da estratégia é impactada pelas ações corretivas necessárias e pelo cenário de incerteza percebida pela turbulência em relação ao futuro.

Para responder a essa questão foi realizada uma pesquisa qualitativa por meio de um estudo de caso (CRESWELL; POTH, 2016). O caso selecionado foi uma indústria da cadeia gráfica localizada no sul de Santa Catarina; a seleção deste objeto se justifica, uma vez que a empresa: (i) sofreu impactos diretos e precisou mudar repentinamente suas estratégias; (ii) presta serviço não essencial; no entanto, (iii) continuou operando com limitações, seguindo as recomendações dos decretos estaduais e municipais frente à pandemia do COVID-19. A coleta de dados foi por meio de entrevistas, levantamento de documentos e observação direta, o que permitiu a triangulação dos dados (CRESWELL; POTH, 2016). A análise ocorreu por meio de análise da narrativa (LIEBLICH et al., 1998) e comparação de padrão teórico/empírico dos dados (TROCHIM, 1989).

A contribuição deste estudo está vinculada a elucidar as práticas adotadas e os desafios enfrentados por uma organização no momento em que o fenômeno se desenvolve em larga escala em nível mundial (JARZABKOWSKI et al., 2019; DOBUSCH; DOBUSCH, 2019).

Passamos a apresentar os conceitos da abordagem da open strategizing, do enfoque contingencial e apresentamos aspectos gerais da evolução da pandemia do COVID-19 nas organizações até o momento da realização deste estudo. Seguimos com a apresentação dos aspectos metodológicos, análise e discussão de como esses fenômenos estão relacionados a partir da perspectiva da open strategizing, e, por fim, apresentamos as contribuições, limitações e indicações para pesquisas futuras.

\section{OPEN STRATEGIZING E FORMAS DE ABERTURA DA ESTRATÉGIA}

Entendemos que os estudos sobre a formação da estratégia ganharam tons mais sociológicos e evoluíram na compreensão pragmática da estratégia, em que o interesse parece recair sobre as ações dos profissionais dentro dos contextos organizacionais. Nessa perspectiva, na qual a estratégia é considerada uma atividade social e situada, que acontece na interação 
entre atores e seus contextos é que surge o strategizing, o "fazer estratégia" ou a "estratégia acontecendo" (ANDERSEN, 2004; WHITTINGTON, 1996, 2006).

O strategizing é caracterizado pela intersecção entre as práticas (atividades orientadas pelo comportamento socialmente aceito na organização), as práxis (microações que formam o processo de construção da estratégia) e os praticantes da estratégia. Essa abordagem ajuda a compreender a complexidade do contexto e das ações que moldam a estratégia organizacional (JARZABKOWSKI; BALOGUN; SEIDL, 2007).

A partir das abordagens sociológicas da estratégia, percebe-se uma abertura gradual do processo de estratégia, que em parte representa os anseios e cobranças dos atores organizacionais dos diversos níveis por mais acesso à informação e maior envolvimento nas conversas sobre estratégia (WHITTINGTON; CAILLUET; YAKIS-DOUGLAS, 2011).

Com as mudanças tecnológicas, culturais e principalmente em função de exigências de mercados cada vez mais competitivos, o formato tradicional de formação da estratégia perde eficiência (WHITTINGTON, 2019). Esse cenário favoreceu a interdependência entre stakeholders, exigindo maior participação e inclusão dos atores organizacionais e maior transparência da informação na tomada de decisão, dando surgimento à open strategy (WHITTINGTON; CAILLUET; YAKIS-DOUGLAS, 2011; MACK; SZULANSKI, 2017).

A open strategizing (estratégia aberta acontecendo) pode ser definida como a conexão entre a prática, as práxis e os praticantes no que se refere às ações de inclusão de atores organizacionais e de transparência da informação no processo de formação da estratégia (JARZABKOWSKI; BALOGUN; SEIDL 2007; WHITTINGTON; CAILLUET; YAKISDOUGLAS, 2011; TAVAKOLI; SCHLAGWEIN; SCHODER, 2017).

Para Hautz (2017), as duas dimensões da open strategizing podem variar ao longo do processo estratégico e ser impactadas pelas contingências internas e ambientais, manifestandose, em maior ou menor grau, dependendo de fatores como cultura e competências gerenciais no aspecto interno, até a maturidade do mercado e o momento econômico, no aspecto externo.

Considerando o conceito de processo de formação da estratégia, entendemos que a abertura da estratégia segue essa abordagem e pode ocorrer de diferentes formas: de forma deliberada, emergente e/ou integradora. A abertura da estratégia ocorre a partir de uma determinação da alta direção, assim como desde o nível operacional, e/ou das duas formas combinadas (MINTZBERG; WATERS, 1985; ANDERSEN, 2000, 2004).

Da mesma forma que estratégias puramente deliberadas ou emergentes não ocorrem, um processo de abertura da estratégia não é tão somente deliberado ou emergente, visto que a primeira significa ausência de aprendizados e neutralidade total do ambiente e a outra significa (1) $\Theta$ REAd | Porto Alegre - Vol. 27 - N. 1 - Janeiro / Abril 2021 - p. 1-34. 
negar a presença de quaisquer intenções e a inexistência de controles. A forma deliberada de abertura possui maior centralização, hierarquização e controle em relação à tomada de decisão; e, no outro extremo, a forma emergente possui maior ênfase nas ações e decisões coletivas, comportamentos criativos e foco no aprendizado (MINTZBERG; WATERS, 1985; ANDERSEN, 2004; MINTZBERG; AHLSTRAND; LAMPEL, 2010; CARDOSO; LAVARDA, 2015; IASBECH: LAVARDA, 2018).

Portanto, o processo de open strategizing, com práticas de inclusão das pessoas e transparência da informação, ocorre de forma deliberada ou imposta quando as atividades e ações são decorrentes de decisões previamente tomadas pela alta direção sem o envolvimento dos diferentes níveis hierárquicos; as decisões são racionais, centralizadas, no sentido top-down (MACK; SZULANSKI, 2017; HAUTZ, 2017; FARACO et al., 2019).

Quando esse processo ocorre no sentido oposto, bottom-up, a partir da iniciativa, demanda ou autonomia dos níveis hierárquicos inferiores, com envolvimento e participação espontânea das pessoas, podemos considerar que o processo de open strategizing ocorre de forma emergente (MINTZBERG; WATERS, 1985; ANDERSEN, 2004; MINTZBERG; AHLSTRAND; LAMPEL, 2010; CARDOSO; LAVARDA, 2015).

Quando o processo estratégico acontece de forma articulada, entre as intenções da alta direção e as participações criativas dos atores envolvidos, o processo de open strategizing ocorre de forma integradora, no sentido middle-up-down, atendendo às condições que são impostas pelas contingências do ambiente (ANDERSEN, 2004; LAVARDA et al., 2010; CARDOSO; LAVARDA, 2015).

\section{INCERTEZA PERCEBIDA PELA TURBULÊNCIA DO AMBIENTE}

Segundo a Teoria Contingencial, a performance econômica das empresas é altamente afetada pela sua estrutura organizacional, pela tecnologia e pelo ambiente externo (BURNS; STALKER, 1961; LAWRENCE; LORSCH, 1967; DONALDSON, 2001). O objetivo dessa teoria é compreender como as organizações se relacionam com os seus ambientes, apontando para a correlação entre as condições ambientais e as práticas estratégicas de uma organização para o alcance dos seus objetivos. Dessa forma, para a Teoria da Contingência, é o ambiente que configura a estrutura de uma organização.

Para Duncan (1972), as dimensões do ambiente podem ser duas: (i) simples/complexo e (ii) estático/dinâmico. A dimensão que trata da complexidade do ambiente pode ser compreendida pelo elevado número de fatores que precisam ser levados em consideração no 
processo de tomada de decisão. Já a dimensão que aborda o dinamismo do ambiente é representada pelo grau em que esses fatores permanecem os mesmos ao longo do tempo ou se estão em um contínuo processo de mudança, não são estáveis.

Duncan (1972) apontou que a combinação desses fatores em ambiente (i) estávelsimples, (ii) complexo-dinâmico, (iii) simples-dinâmico ou (iv) estável-complexo leva a diferentes graus de incerteza percebida. Assim, dependendo das características do ambiente em que se encontra, a organização vai experimentar maior ou menor incerteza ambiental, tendo maior ou menor dificuldade em obter informações relevantes do ambiente para a tomada de decisão. Se a organização estiver inserida em ambiente dinâmico-complexo, devido à própria natureza de mudança contínua, enfrentará maior incerteza na tomada de decisão.

Para fins desta pesquisa, delimitamos a combinação dos fatores em ambiente complexodinâmico como a principal dimensão que causa a incerteza ambiental percebida (DUNCAN, 1972; PRIGOGINE, 1996). A natureza complexa e dinâmica do ambiente vai influenciar na percepção dos gestores da organização para a tomada de decisão de forma diferente, pois alguns indivíduos apresentam maior grau de tolerância ao risco e incerteza, podendo perceber algumas situações como menos incertas do que outras.

Com base nos pressupostos da teoria da contingência, a escola ambiental de pensamento estratégico foi revisitada por Mintzberg, Ahlstrand e Lampel (2010), que apontam para quatro dimensões que impactam e alteram o ambiente em que as organizações estão inseridas - e, consequentemente, a sua estratégia. São elas: (i) estabilidade do ambiente, que vai do estável ao dinâmico, alterado de acordo com situações que estão fora do controle da organização e que são imprevisíveis, sem padrão reconhecido; (ii) complexidade do ambiente que impacta o nível de conhecimento necessário para a entrega de valor; conforme a organização acumula conhecimento, o nível de complexidade do ambiente é alterado e diminui, podendo variar de simples a complexo; (iii) diversificação do ambiente, que está relacionada com os mercados em que a organização atua, podendo variar de integrados a diversificados; e (iv) hostilidade ambiental, que depende da concorrência, relações de trabalho, disponibilidade de recursos, entre outros; variando de favorável a hostil (MINTZBERG; AHLSTRAND; LAMPEL, 2010).

Para delimitar o entendimento das condições ambientais para o desenvolvimento da tomada de decisão e o fazer estratégico, associamos os pressupostos de Duncan (1972) e Mintzberg, Ahlstrand e Lampel (2010) considerando que as características ou dimensões do ambiente influenciam no grau de incerteza percebida pela organização, que está, consequentemente, relacionada com a abertura da estratégia. Portanto, delimitamos que as características de ambiente estático/dinâmico e simples/complexo caracterizam a turbulência 
do ambiente e influenciam na incerteza percebida pela organização, a qual condiciona as decisões de inclusão das pessoas e as práticas estratégicas de transparência da informação, elementos da open strategizing.

A teoria da contingência sustenta que a estratégia é moldada pelo ambiente em que a organização está inserida. Nesse contexto, cada dimensão ambiental vai influenciar a formação da estratégia (DUNCAN, 1972; MINTZBERG; AHLSTRAND; LAMPEL, 2010) e, consequentemente, a forma como ocorre a abertura dessa estratégia (HAUTZ, 2017).

Neste sentido, as perspectivas da teoria da contingência apontam para o grau de influência que uma situação de pandemia pode representar para uma organização, por exemplo. A forma como ocorre a abertura da estratégia, nesse sentido, é impactada pelas ações corretivas imediatamente necessárias e, principalmente, pelo cenário de incerteza percebida em relação ao futuro nesse ambiente.

Com as reflexões teóricas apresentadas e buscando responder à questão de pesquisa inicial, elaboramos uma proposição norteadora para a fase empírica deste estudo: o processo de open strategizing, com práticas de inclusão das pessoas e transparência da informação, ocorre de forma: (i) deliberada, (ii) emergente ou (iii) integradora, visando a responder a incerteza percebida pela turbulência do ambiente, causada pela pandemia do COVID-19 (MACK; SZULANSKI, 2017; TAVAKOLI; SCHLAGWEIN; SCHODER, 2017).

\section{ASPECTOS METODOLÓGICOS}

Considerando o objetivo desta pesquisa, que foi compreender como ocorre o processo de open strategizing frente à incerteza percebida pela turbulência do ambiente causada pela pandemia do COVID-19, classificamos este estudo como multiparadigmático (GIOIA; PITRE, 1990), visto que se fundamenta na zona de transição entre os paradigmas interpretativista e funcionalista (BURRELL; MORGAN, 1979). Ao mesmo tempo em que buscamos analisar práticas estratégicas socialmente construídas como um processo contínuo, uma característica do interpretativismo, também examinamos as regularidades presentes nesse processo, o que aponta para a perspectiva funcionalista (GIOIA; PITRE, 1990).

Quanto à abordagem, esta pesquisa classifica-se como qualitativa, empregando o método estudo de caso (CRESWELL; POTH, 2016), que permite o alcance em profundidade do fenômeno, uma vez que enfoca o caso em sua singularidade e proporciona a perspectiva micro-organizacional de estudo da estratégia como prática social. "Os estudos de caso são generalizáveis a proposições teóricas, e não a populações ou universos” (YIN, 2018, p. 58). 
Nesse sentido, este estudo de caso não representa uma "amostragem", e nosso objetivo é expandir e generalizar teorias (generalização analítica) e não enumerar frequências (generalização estatística), de acordo com Yin (2018, p. 97).

O estudo de caso único, como ressalta Yin (2018, p. 97), pode ser justificado sob cinco aspectos: caso crítico, peculiar, comum, revelador ou longitudinal. Destacamos que este caso apresenta as peculiaridades de um caso comum. As circunstâncias e condições de ocorrências de situações práticas e cotidianas deste caso são as de um empreendimento de pequeno porte; e propiciaram elementos significativos para a abordagem qualitativa, que busca a profundidade, a essência e o significado que as pessoas e os grupos atribuem para cada situação, na construção e interação de processos sociais relacionados ao interesse da questão de pesquisa (CRESWELL; POTH, 2016; YIN, 2018, p. 98).

O caso selecionado como objeto de estudo se justifica como caso comum por diferentes características: (i) a luta para manter-se em funcionamento por causa das restrições e das recomendações sanitárias, pela queda de receita devido à baixa demanda e pela dificuldade de liberação de recursos do governo às pequenas e médias empresas; (ii) empresa de gestão familiar, com capital de giro limitado (que para muitas empresas foi insuficiente para manterse durante a pandemia); (iii) sofrer impactos diretos e precisar mudar repentinamente suas estratégias; (iv) prestar serviço não essencial; e, no entanto, (v) continuar operando com limitações, seguindo as recomendações dos decretos estaduais e municipais, frente à pandemia do COVID-19 (enquanto outras empresas do mesmo porte encerraram suas atividades). Ademais, a empresa proporcionou abertura e transparência das informações para coleta dos dados, cumprindo o critério de intencionalidade de pesquisa e acessibilidade aos dados, possibilitando estudar o fenômeno.

A empresa selecionada foi uma indústria da cadeia gráfica localizada no sul de Santa Catarina. Por motivo de confidencialidade foi designada como Grafix. Fundada em 1986, a Grafix é uma empresa familiar de primeira geração, que em 2008 direcionou sua produção para o mercado editorial, especializando-se na confecção de livros, revistas e periódicos por meio da tecnologia de impressão offset. Atualmente, atende organizações governamentais e instituições privadas em quase todas as regiões do Brasil (exceto a região norte). A Empresa foi impactada pelo primeiro decreto de emergência (515), do dia 17 de março de 2020, que determinava que as indústrias do Estado operassem em sua capacidade mínima necessária, em regiões de contaminação comunitária do COVID-19. O Decreto 525, do dia 23 de março, definiu novas regras para as indústrias de todas as cidades de Santa Catarina, como a redução mínima de $50 \%$ da força de trabalho para continuidade da operação e a adoção de medidas 
preventivas. O último decreto estadual (562) foi do dia 23 de abril de 2020, determinando estado de calamidade pública em todo o Estado por um período de 180 dias, prorrogando as medidas de segurança do decreto anterior até novo decreto (SES, 2020).

De acordo com os documentos facilitados pela própria organização, a Grafix possuía, até o começo da pandemia, 38 funcionários, enquadrando-se nos requisitos de EPP (empresa de pequeno porte) conforme o SEBRAE (2013).

A coleta de dados desenvolveu-se pelas técnicas de: (i) entrevistas semiestruturadas; (ii) levantamento de documentos; e (iii) observação direta (CRESWELL; POTH, 2016).

As (i) entrevistas semiestruturadas ocorreram presencialmente, com um grupo de praticantes da Grafix, que foram denominados como Entrevistados (E): (E01) líder de produção; dois analistas administrativos, (E02) de RH e (E03) Comercial; (E04) operador de máquinas; e (E05) auxiliar de produção. As entrevistas foram gravadas com consentimento dos entrevistados, com duração média de 30 minutos cada; foram, posteriormente, transcritas em arquivo Word gerando, aproximadamente, 10.600 palavras. As entrevistas ocorreram na última semana do mês de abril de 2020 e foram realizadas a partir de um roteiro com questões abertas, atreladas à questão de pesquisa inicial como norteadora: como ocorre o processo de open strategizing frente à incerteza percebida pela turbulência do ambiente causada pela pandemia do COVID-19? As questões foram tanto objetivas (sobre as mudanças de rotinas e práticas) quanto subjetivas (sobre suas emoções e sentimentos).

O (ii) levantamento dos documentos consistiu na busca de documentos elaborados pela própria organização antes e durante o período da pandemia, como publicações e comunicados internos, bem como em decretos governamentais. Até o momento da conclusão deste estudo foram cinco decretos municipais, entre eles o decreto de situação de emergência, do dia 19 de março (MUNICÍPIO DE TUBARÃO, 2020).

A (iii) observação direta e as respectivas anotações de campo foram feitas durante o início e o desenrolar da pandemia. Um dos pesquisadores estava inserido na organização em estudo, e, consequentemente, observando in loco as rotinas dos praticantes e os esforços realizados durante o processo, fato que permitiu corroborar as questões mencionadas durante as entrevistas e nos documentos analisados.

A partir dessas três fontes foi possível realizar a triangulação dos dados, conferindo maior credibilidade na interpretação e apresentação dos mesmos. Na fase de análise dos dados, adotamos as técnicas de pattern matching (TROCHIM, 1989) e de análise da narrativa (LIEBLICH et al., 1998) das entrevistas.

Para melhor condução da etapa de análise dos resultados e alinhados com a proposição 
teórica, foram definidos elementos constitutivos do estudo (ECE), desmembrados em elementos operacionais do estudo (EOE) a partir de Kerlinger (1979) (Quadro 1).

Quadro 1. ECEs e EOEs

\begin{tabular}{|c|c|c|c|}
\hline $\begin{array}{l}\text { Questão de } \\
\text { pesquisa }\end{array}$ & Proposição & ECE & EOE \\
\hline \multirow{3}{*}{$\begin{array}{l}\text { Como ocorre o } \\
\text { processo de } \\
\text { open } \\
\text { strategizing } \\
\text { frente à } \\
\text { incerteza } \\
\text { percebida pela } \\
\text { turbulência do } \\
\text { ambiente } \\
\text { causada pela } \\
\text { pandemia do } \\
\text { COVID-19? }\end{array}$} & \multirow{3}{*}{$\begin{array}{l}\text { O processo de open } \\
\text { strategizing, com práticas de } \\
\text { inclusão das pessoas e } \\
\text { transparência da informação, } \\
\text { ocorre de forma (i) } \\
\text { deliberada, (ii) emergente ou } \\
\text { (iii) integradora, visando a } \\
\text { responder a incerteza } \\
\text { percebida pela turbulência } \\
\text { do ambiente, causada pela } \\
\text { pandemia. }\end{array}$} & ECE1: Open Strategizing & $\begin{array}{l}\text { EOE1.1: Práticas } \\
\text { participativas e inclusivas } \\
\text { EOE1.2: Práticas de } \\
\text { transparência da informação }\end{array}$ \\
\hline & & $\begin{array}{l}\text { ECE2: Formas de } \\
\text { Abertura da Estratégia }\end{array}$ & $\begin{array}{l}\text { EOE2.1: Forma deliberada } \\
\text { EOE2.2: Forma emergente } \\
\text { EOE2.3: Forma integradora }\end{array}$ \\
\hline & & $\begin{array}{l}\text { ECE3: Incerteza } \\
\text { Percebida pela } \\
\text { Turbulência do } \\
\text { Ambiente }\end{array}$ & $\begin{array}{l}\text { EOE3.1: Complexidade } \\
\text { EOE3.2: Dinamismo }\end{array}$ \\
\hline
\end{tabular}

Fonte: Elaboração própria.

Assim, a partir das categorias ou elementos de análise ECE1: Open Strategizing, ECE2: Formas de Abertura da Estratégia e ECE3: Incerteza Percebida pela Turbulência do Ambiente, passamos à análise e discussão dos resultados dos dados encontrados.

\section{ANÁLISE E DISCUSSÃO DOS RESULTADOS}

Apresentamos, inicialmente, aspectos gerais referentes à evolução da epidemia do COVID-19. A seguir, apresentamos a triangulação dos dados coletados nas narrativas das entrevistas, na observação direta, com as respectivas notas de campo, e nos documentos levantados de forma abdutiva, proporcionando elementos suficientes para fomentar a análise conjunta por meio dos elementos constitutivos do estudo e seus respectivos elementos operacionais (EOEs).

Em 11 de março de 2020, a OMS declarou como pandemia o surto causado pelo SARSCoV-2, o vírus que causa a doença do COVID-19 (WHO, 2020). O primeiro caso da doença foi identificado no dia $1^{\circ}$ de dezembro de 2019 na cidade de Wuhan, na China, e oficialmente reportado no dia 31 de dezembro. No Brasil, o primeiro caso confirmado da doença ocorreu em São Paulo, no dia 25 de fevereiro (MINISTÉRIO DA SAÚDE, 2020). Até o dia 31 de maio de 2020, foram confirmados mais de 6 milhões de casos e aproximadamente 369 mil mortes, em pelo menos 188 países e territórios; no Brasil, haviam sido confirmados aproximadamente meio milhão de casos e 30 mil mortes. No final de 2020, antes do encerramento desta pesquisa, foram registrados mais de 71 milhões de casos no mundo e mais de 1,6 milhão de mortes; no Brasil, 
o número de casos se aproximava dos 7 milhões, com mais de 187 mil mortes. Em Santa Catarina, mais de 460 mil pessoas já foram infectadas, ultrapassando 4.700 mortes, sendo que o ritmo de crescimento desses números continua sem controle.

Para tentar conter a pandemia, uma série de regras de isolamento foram determinadas em forma de decretos em nível nacional, estadual e municipal. Em Santa Catarina, as empresas foram impactadas pelo primeiro decreto de emergência (515), de 17 de março de 2020, que determinava que as indústrias do Estado operassem em sua capacidade mínima necessária em regiões de contaminação comunitária do COVID-19 (SES, 2020). Posteriormente, o decreto 525 , de 23 de março, definiu novas regras para as indústrias, como a redução mínima de $50 \%$ da força de trabalho para continuidade da operação e a adoção de medidas preventivas. O último decreto estadual (562) foi de 23 de abril de 2020, determinando estado de calamidade pública em todo o Estado por um período de 180 dias, prorrogando as medidas de segurança do decreto anterior até novo decreto (SES, 2020).

Com todas essas restrições e medidas de isolamento da população, a economia mundial tem sido severamente impactada. O Fundo Monetário Internacional (FMI) projeta que o Produto Interno Bruto (PIB) mundial deve cair 3\% em 2020, o que representa, segundo o FMI, a maior retração desde os anos 1930. A Zona do Euro deve ser a mais afetada (previsão de queda de 7,5\% do PIB). No Brasil, o FMI estima uma retração do PIB de 5,3\% em 2020. O próprio FMI reconhece que a crise atual não tem precedentes na história recente e que as projeções sofrerão ajustes dependendo da duração e da intensidade da crise e da gradativa retomada (WHO, 2020).

\subsection{ECE1: OPEN STRATEGIZING}

As práticas participativas e inclusivas dos atores organizacionais e as práticas de transparência da informação são caracterizadas pelas ações que favorecem e ampliam a participação de atores organizacionais e que aumentam a visibilidade das informações estratégicas durante o processo de tomada de decisão (WHITTINGTON; CAILLUET; YAKISDOUGLAS, 2011; HAUTZ; SEIDL; WHITTINGTON, 2017).

\subsubsection{EOE1.1: práticas participativas e inclusivas}

Na Grafix, as práticas participativas e inclusivas foram identificadas como (i) Reuniões Formais; (ii) Reuniões Informais; (iii) Episódio de Brainstorming; e (iv) Briefings. 
(i) Reuniões Formais. Para Seidl e Guerard (2015), as reuniões são consideradas uma das práticas mais comuns nas organizações, nas quais diferentes visões estratégicas podem ser compartilhadas e contestadas, podendo ser definidas como uma prática ou evento comunicativo planejado e episódico que envolve vários participantes colocados no mesmo espaço (físico ou virtual) e cujo objetivo é ostensivamente relacionado ao funcionamento da organização.

Durante as entrevistas percebemos que as principais práticas de participação e inclusão dos atores organizacionais foram as reuniões, inicialmente com intuito de definir quais medidas de segurança sanitária precisavam ser adotadas na empresa. A primeira reunião aconteceu após o primeiro decreto municipal, e além da presença dos sócios e dos representantes dos setores administrativos, houve a inclusão da líder de produção nas discussões.

Esta reunião foi um divisor de águas e marcou o momento em que o primeiro escalão da empresa compreendeu a gravidade da situação e caráter atípico das decisões que deveriam tomar diante uma crise sem precedentes. A reação imediata foi buscar soluções junto com a equipe administrativa, abrindo a discussão sobre os problemas imediatos da empresa.

As discussões foram conduzidas por um sócio fundador, que liderou de forma participativa. O Entrevistado E02 relatou que esta é uma prática comum na organização:

\footnotetext{
Essa questão da liderança participativa eu acho que acontece muito aqui. Eles [sóciosfundadores] são bem transparentes em relação às atitudes que eles querem tomar, o que estão pensando em fazer. [...] A gente sempre participa muito, é sempre muito aberto, sempre participa bastante das decisões que eles querem tomar (E03).
}

As discussões da reunião formal envolveram a determinação e a sincronização de ação futura, agrupamento e distribuição de informação e distribuição e monitoramento de tarefas (SEIDL; GUERARD, 2015).

(ii) Reuniões Informais. A prática de reuniões pode influenciar a estratégia de diferentes ângulos. Além das reuniões formais, os encontros não planejados previamente, as reuniões informais, são práticas discursivas que afetam o desenvolvimento de visões compartilhadas sobre questões estratégicas, possibilitam a "conversa estratégica" e o fazer estratégico (SPEE; JARZABKOWSKI, 2011). Essas reuniões favorecem a discussão sobre a maneira como as questões estratégicas são discutidas e avaliadas, servem para negociar e chegar a acordo sobre ação coletiva, muitas vezes de forma mais ágil que as reuniões formais e influenciam a formação da estratégia (SEIDL; GUERARD, 2015).

Identificamos que a definição de antecipação de férias, demissões, reduções e suspensões de contrato dos colaboradores ocorreram por meio de reuniões informais entre a analista de recursos humanos, os sócios-fundadores e a líder de produção. Além da diminuição 
da demanda, as medidas de afastamentos exigiram adequação no quadro de pessoal da empresa.

$\mathrm{O}$ entrevistado E02, analista de recursos humanos, revelou que (até o momento da entrevista) a redução por demissão já estava em 30\% dos colaboradores da Grafix.

Segundo relato da líder de produção, E01, a definição daqueles trabalhadores da produção que teriam suas férias antecipadas ou que seriam desligados da empresa aconteceu informalmente, com bastante espaço para discussão entre os envolvidos: "E eles [sóciosfundadores] passam para o RH e a administração que cuida mais de produção e a gente vai debatendo juntos" (E01). E01 complementa ainda que:

Eu me sinto na parte de demissões, até porque como eu comando a produção, eu tive meio que optar pelas pessoas que mais fossem vestir a camisa da empresa e continuar lutando por ela. Eu e a administração, o RH, a gente sentou e... a ordem veio, claro, da gerência da empresa, veio dos superiores, e perante a ordem a gente foi administrando e meio que escolhendo, assim, e vendo quais as pessoas seriam necessárias manter aqui e as pessoas que não (E01).

A partir dessa explicação, entendemos que a decisão referente à redução do quadro de funcionários já havia sido tomada pelos sócios-fundadores, na reunião formal. No entanto, a líder de produção teve abertura para colaborar e, de certa forma, a partir de encontros informais, definir quais funcionários continuariam na empresa. Como argumentaram Whittington, Cailluet e Yakis-Douglas (2011) e Hautz, Seidl e Whittington (2017), a abertura, na verdade, não diz respeito à democracia na tomada de decisão, mas à disseminação de informações estratégicas a mais pessoas capazes de participarem dessas interações. Inclusive, o entrevistado E01 afirmou que é sempre dessa forma que funciona na empresa: “As decisões mais sérias são tomadas por eles".

(iii) Episódio de Brainstorming. O brainstorming é uma prática participativa (HAUTZ, 2017) adotada para gerar soluções criativas para problemas organizacionais; combina uma abordagem informal de solução de problemas com o pensamento lateral; incentiva as pessoas a apresentarem pensamentos e ideias que podem inicialmente parecer sem sentido, no entanto, a partir dessas ideias podem ser geradas soluções originais e criativas (ALMUTAIRI, 2005).

O brainstorming foi adotado e identificado em uma nova reunião realizada para elaborar estratégias de marketing para alavancar as vendas durante o período de crise. Nesse episódio, que teve a participação dos gestores de topo e de representantes dos demais setores, discutiu-se a situação da empresa e abriu-se um espaço livre para que ideias criativas pudessem emergir e ajudassem a enfrentar a crise e manter a empresa.

Como descreveu E03, o cenário não era animador, pois, com a retração, muitos clientes e empresas haviam encerrado suas atividades sem previsão de retorno, o que acarretou a drástica

REAd | Porto Alegre - Vol. 27 - N.․1 - Janeiro / Abril 2021 - p. 1-34. 
diminuição da demanda naquele momento, prejudicando o fluxo de caixa. A solução surgiu da participação de um colaborador e apontava para a eliminação da margem de lucro de todos os serviços durante o mês de abril com intuito de incentivar a contratação de novos serviços. O entrevistado E03, analista comercial, destacou essa ação em seu relato:

Geralmente é feita uma reunião e é conversado [...]. E eles, a direção, também apresenta a sugestão deles e às vezes, se não é definido naquela reunião, volta a ser conversado. E, agora na crise, foi bem rápido para conversar sobre o que estava acontecendo, foi visto que precisava de mais vendas. E, da parte da ação de vendas, foi mais informal, foi mais o grupo, a parte de atendimento e de orçamento (E03).

Considerando as práticas participativas e inclusivas dos atores organizacionais, notamos que a situação de crise proporcionou uma oportunidade de inclusão dos participantes na tomada de decisão da organização e a chance de opinar trouxe alternativas criativas para que a organização pudesse se manter funcionando apesar do contexto de turbulência. Por meio da observação de um dos pesquisadores presentes nessa reunião, onde ocorreu o brainstorming, destacamos que a interação entre os membros não se limitava pelas hierarquias e prevalecia as melhores ideias e alternativas para o enfrentamento dos problemas.

(iv) Briefing. A conversa informativa, briefing conversation ou briefing section, é caracterizada pelo conjunto de instruções ou informações iniciais de um projeto ou processo, que pode ser escrita ou oral, detalhada ou difusa; um conjunto de interações que ocorrem para desenvolver um entendimento mútuo sobre um novo projeto (PATON; DORST, 2011). Embora as principais decisões já tivessem sido definidas, muitas por determinações governamentais, ainda havia espaço para os chamados "ajustes finos", que aconteceram por meio de conversas diretas entre lideranças e operários nos momentos em que as diretrizes foram repassadas.

As pautas em geral envolviam as ações preventivas acatadas pela organização em relação à doença COVID-19, formas de evitar o contágio e a proliferação do vírus no ambiente organizacional. Desta forma, o briefing serviu para reforçar as ações referentes às tarefas ou informar as mudanças no padrão das tarefas, pois o que era realizado de uma determinada maneira teve que ser modificado para atender às exigências sanitárias, por exemplo "as coisas mudaram, agora temos que tomar cuidados com o distanciamento, usar as máscaras, etc.” (E01).

Assim, as práticas participativas e inclusivas na Grafix caracterizaram o strategizing ou a "estratégia acontecendo", compreendendo as ações, as interações e o contexto em que as estratégias aconteceram (WHITTINGTON, 2006). Essas práticas foram essenciais para fortalecer a inclusão dos atores, fortalecer a organização para se enfrentar a turbulência do ambiente e proporcionar as práticas de transparência da informação. 


\subsubsection{EOE1.2: práticas de transparência da informação}

As práticas de transparência correspondem à visibilidade das informações estratégicas durante o processo de formação estratégica (WHITTINGTON; CAILLUET; YAKISDOUGLAS, 2011; HAUTZ; SEIDL; WHITTINGTON, 2017).

Na Grafix, a principal motivação para o aumento da transparência nas informações foi decorrente do ambiente externo, pela situação crítica gerada pela pandemia do COVID-19 que já era uma realidade para a organização. O primeiro passo dado pela direção foi proporcionar informação a todos os colaboradores de quais seriam as medidas legais que a organização precisaria adotar, e que isso implicaria mudanças de comportamentos, hábitos e rotinas (WHITTINGTON, 2006; JARZABKOWSKI; BALOGUN; SEIDL, 2007). A líder de produção ficou autorizada a repassar todas as informações e decisões debatidas na reunião em que se definiram as medidas de segurança sanitária, esclarecendo os novos procedimentos que deveriam ser adotados nas rotinas de trabalho com o intuito de evitar o contágio e a consequente proliferação do COVID-19.

Essas informações foram reforçadas pela analista de $\mathrm{RH}$, com conversas informais e individuais (práxis) com cada um dos colaboradores, segundo explicou o entrevistado E05: "Até a menina do RH também comunicou a gente, [...] ela passou em cada um, explicando sobre uso obrigatório da máscara e o álcool em gel disponibilizado”. Todas as informações que existiam sobre os cuidados foram repassadas. Inicialmente, no entanto, muitas informações externas eram desencontradas, fazendo com que a direção demorasse em agir. Levou alguns dias até se posicionar e passar a articular essas informações com os demais atores.

O entrevistado E01 relatou que inicialmente não havia uma comunicação clara por parte da direção para a produção, sobre como a empresa reagiria ao cenário de pandemia:

Desde o princípio, lá quando estava todo o tumulto de que as empresas estavam fechando, disso e daquilo, foi bem remota a comunicação. Foi passado, assim, mais para a questão de escritório, e foi passado para eu passar para eles, mas ficou meio vago. Tanto que a produção estava meio borbulhante, estavam parando um e parando outro quando iam para a produção, porque eles estavam querendo informação (E01).

No entanto, o entrevistado E02, que participou de todas as reuniões estratégicas relativas à pandemia, relatou que essa falta de transparência inicial aconteceu também com os colaboradores da administração:

$\mathrm{Eu}$ acho que no começo a gente teve uma resistência bem grande em relação ao que estava acontecendo. Talvez negar que isso tudo estava acontecendo para que a gente se acalmasse um pouco, estava todo mundo muito agitado com o que estava acontecendo. E eu acho que eles aguentaram um pouquinho a informação ou ficaram 
um pouco mais na deles para não, talvez, não deixar transparecer, não deixar a gente um pouco mais nervosa e tal. Eu acho que no começo aconteceu isso (E02).

Devido à falta de repasse de informações (incertezas percebidas no ambiente), os próprios colaboradores fizeram pressão para que houvesse o repasse das informações a respeito dos decretos e de como a empresa reagiria ao cenário de pandemia. No caso da produção, os colaboradores se reuniram informalmente para conversar sobre o assunto e buscaram a analista de recursos humanos, que no momento não tinha informações suficientes, para que desse algum direcionamento oficial para os colaboradores de como eles deveriam se portar (se iriam trabalhar ou poderiam ficar em casa). O entrevistado E05, auxiliar de produção, relatou:

\footnotetext{
A gente também se reuniu com a menina do RH para perguntar e ela também disse que até onde eles sabiam o decreto que era para nós permanecermos aberta. Eu acredito que não todo mundo, mas algumas pessoas, a gente se reuniu. E perguntou para ela, e ela esclareceu tudo para nós, que o decreto não era de tudo fechar, que a indústria poderia ficar aberta e a gente entendeu essa parte (E05).
}

Depois disso é que houve a reunião em que as informações oficiais foram repassadas, e tudo foi esclarecido aos colaboradores. O episódio mais perceptível foi no processo de formação da estratégia de marketing, no qual houve pouca transparência das informações para demais níveis atingidos por essas ações.

Podemos identificar que, entre os sócios-fundadores e alguns membros internos de outros níveis hierárquicos da empresa (praticantes internos), houve sinergia colaborativa para definir diretrizes de enfrentamento à crise causada pela pandemia do COVID-19, o que leva à compreensão de que a open strategizing foi identificado em diferentes episódios na Grafix durante esse período.

\subsection{ECE2: FORMAS DE ABERTURA DA ESTRATÉGIA}

A partir da articulação entre o conceito de formação da estratégia Andersen (2004) e de open strategizing (HAUTZ, 2017), a abertura da estratégia acontece de diferentes formas. O processo de open strategizing pode ocorrer de forma deliberada, no sentido top-down; no sentido oposto, bottom-up, a partir da iniciativa dos níveis hierárquicos inferiores, de forma emergente ou autônoma; e, quando acontece de forma articulada, combinada, com práticas de inclusão das pessoas e transparência da informação, ocorre de forma integradora ou middle-updown, atendendo às condições que são impostas pelas contingências do ambiente (ANDERSEN, 2004; JARZABKOWSKI; BALOGUN; SEIDL, 2007; WHITTINGTON; CAILLUET; YAKIS-DOUGLAS, 2011; HAUTZ, 2017; MACK; SZULANSKI, 2017; 
TAVAKOLI; SCHLAGWEIN; SCHODER, 2017).

É importante destacar que a forma como este processo de abertura ocorre e o desenvolvimento do processo per se estão separados apenas conceitualmente; na prática é complexo identificar esta separação.

\subsubsection{EOE2.1: forma deliberada}

O processo de open strategizing, com práticas de inclusão das pessoas e transparência da informação, ocorre de forma deliberada ou imposta quando as atividades e ações são decorrentes de decisões previamente tomadas pela alta direção sem o envolvimento dos diferentes níveis hierárquicos. As decisões são racionais, centralizadas, e o processo é imposto no sentido top-down (MACK; SZULANSKI, 2017; TAVAKOLI; SCHLAGWEIN; SCHODER, 2017; FARACO et al., 2019).

Em nossas análises encontramos dois episódios estratégicos que podem ser caracterizados como a forma deliberada de open strategizing, se aproximando do conceito de deliberação, por meio das intenções pretendidas e planejadas que foram realizadas de acordo com objetivos e propósitos definidos pela alta direção (MINTZBERG; WATERS, 1985): episódios estratégicos de (i) adaptação e (ii) sobrevivência.

(i) Adaptação. O primeiro episódio de (i) adaptação é de ordem sanitária e diz respeito às medidas de enfrentamento do contágio do COVID-19 na organização. Para permanecer em atividade, a indústria necessitava adequar-se imediatamente às novas regras de segurança sanitária, determinadas pelos decretos governamentais (SES, 2020). A principal preocupação identificada foi a de manter as decisões alinhadas à estratégia geral da empresa, porém não poderiam contrariar as determinações governamentais. As reuniões realizadas ocorreram a partir das demandas do ambiente externo e foram conduzidas pela alta direção. No princípio, embora a diretoria estivesse disposta a permitir maior abertura da estratégia, com a maior inclusão de pessoas nas reuniões, havia pouca margem para discussões e alternativas, conduzindo à redução da criatividade e autonomia das pessoas (MINTZBERG; WATERS, 1985).

Portanto, consideramos que neste episódio a forma deliberada foi predominante, pois as ações de combate ao contágio e a determinação de fechamento da organização foram planejadas pela alta direção e repassadas aos demais funcionários no sentido top-down.

(ii) Sobrevivência. Este episódio foi principalmente de ordem financeira e está relacionado com a crise econômica gerada pela pandemia de COVID-19, que afetou também o 
mercado gráfico, impactando nas medidas de afastamento de pessoal, necessárias para a diminuição dos riscos de contágio da doença.

As principais opções foram enxugar o quadro de pessoal e reduzir os custos fixos, principalmente salários. Entre as medidas adotadas, estavam as demissões e férias compulsórias, a suspensão de contrato e a redução de carga horária. Novamente, as reuniões foram as práticas mais utilizadas para fomentar a tomada de decisão, com a inclusão na conversa estratégica de alguns representantes dos setores que seriam mais afetados, como podemos destacar no relato do líder de produção (E01).

Eu e a administração, o RH, a gente sentou e... a ordem veio, claro, da gerência da empresa, veio dos superiores, e perante a ordem a gente foi administrando e meio que escolhendo, assim, e vendo quais as pessoas seriam necessárias manter aqui e as pessoas que não... que dariam para esperar mais um pouco, sabe?

Percebemos que as reuniões foram motivadas pelos interesses da alta direção, com pautas preestabelecidas. As principais decisões ficaram restritas aos cargos mais elevados, e houve pouca amplitude no diálogo, que não foi aberto aos demais funcionários da indústria. Quase todos sentiram falta de mais diálogo, com destaque para os relatos de:

(E04 - Operador de Máquinas) Na minha opinião, uma coisa que faltou foi uma reunião com todo mundo, para explicar para todo mundo, em vez de explicar individual para um e para outro, entendeu?

(E03 - Analista Comercial) Ah, eu não tenho nem muita noção, porque me colocar no lugar assim é bem difícil, né, mas eu acho que [precisa] conversar mais.

Pelos relatos percebemos que a opção de não dialogar abertamente com todos os funcionários e informar, de forma particular e apenas às pessoas afetadas diretamente pelas decisões de redução de custos com pessoal, gerou mais insegurança aos funcionários quanto à manutenção de seus empregos. Além disso, as medidas de redução de pessoal geraram um aumento de atribuições aos funcionários que permaneceram, e isso também pode ter dificultado o maior engajamento com o processo. Isso ficou evidenciado no relato do entrevistado E04, ao ser questionado sobre sua inclusão no processo:

Se eu gostaria de ser incluído? Sim e não! Sim, porque eu sou uma pessoa que está há quase 14 anos aqui dentro, então, eu me considero importante para empresa também, em ajudar a empresa a crescer. E não porque eu já tenho bastante compromisso lá atrás [produção], e isso poderia me atrapalhar, mas também não teria negado e teria ajudado.

Neste episódio, ficou evidente o potencial para abertura da estratégia, porém, esta foi limitada pela forma deliberada como ocorreu, evidenciada pela centralização, hierarquização e controle em relação à tomada de decisão (ANDERSEN, 2004; HAUTZ, 2017). 


\subsubsection{EOE2.2: forma emergente}

A forma emergente possui maior ênfase nas ações e decisões coletivas, comportamentos criativos e foco no aprendizado, com padrões e comportamentos realizados ao longo do tempo com ausência de intenções ou planejamentos (MINTZBERG; WATERS, 1985; ANDERSEN, 2004; CARDOSO; LAVARDA, 2015; MACKAY; CHIA; NAIR, 2020).

Entendemos que a abertura da estratégia pode ocorrer de forma emergente por meio de ações realizadas pela organização que não foram expressamente pretendidas, previstas ou estabelecidas pelo planejamento estratégico (MINTZBERG; WATERS, 1985), mas sim geradas na prática por meio de ações autônomas (ANDERSEN, 2000), que possibilitam soluções estratégicas criativas, surgidas nos diversos níveis da organização, não se restringindo ao nível de alta direção (ANDERSEN, 2004). As ações, atitudes e comportamentos realizados de forma não planejada são importantes aprendizados organizacionais, que podem ser introduzidos aos poucos no novo padrão de comportamento que surgiu a partir das mudanças inseridas em decorrência da incerteza e turbulência do ambiente.

Nesse contexto, percebemos dois episódios que podem ser destacados como forma emergente de open strategizing: (i) ações de vendas e (ii) briefings e reuniões informais.

(i) Ações de vendas. Durante o período em que foi solicitado aos funcionários ampliar os esforços de vendas de modo a criar receitas, foi definido pelos próprios colaboradores do setor comercial que seriam empregadas ferramentas de marketing digital com baixo custo, basicamente, o uso de e-mails e redes sociais. Entretanto, os funcionários responsáveis por estas práticas perceberam que as ferramentas digitais não estavam captando novos clientes e que muitos dos clientes antigos não retornavam as mensagens. Foi então que começaram a investir em outra ação, o contato telefônico. Essa prática, já pouco utilizada antes do confinamento, se mostrou mais eficiente, apesar do desafio de localizar os clientes, que já não estavam mais em seus escritórios físicos, visto que a determinação de isolamento social atingiu a todos. A partir disso, os contatos telefônicos voltaram a ser a ferramenta mais usada pela equipe de vendas, como podemos observar no relato da analista comercial, E03:

O contato com os clientes também está bem diferente, porque já não tá tão acessível como era antes [...] antes, a gente ainda conseguia falar por telefone, agora fica por email ou pelo WhatsApp, então, se eles não querem responder, eles não respondem. Algumas editoras já trabalhavam em home office, mas algumas, que tinham um lugar físico, não estão mais atendendo naquele telefone, né? (E03).

Portanto, essa ação de vendas foi mais informal, partiu do grupo, foi elaborada e decidida de forma emergente, no sentido bottom-up (MINTZBERG; WATERS, 1985; 
ANDERSEN, 2004; CARDOSO; LAVARDA, 2015).

(ii) Briefings e Reuniões informais. Outras formas emergentes de abertura da estratégia foram identificadas nos briefings e reuniões informais. Ambas por iniciativas dos próprios funcionários que necessitavam de mais transparência nas informações e maior inclusão nas conversas estratégicas. Muitos buscaram os seus líderes em pequenos grupos para tratarem das mudanças que estavam ocorrendo na organização.

Os setores passaram a dar briefings informando aos seus funcionários, atualizando-os das mudanças e novas diretrizes sempre que estas eram definidas. Esta iniciativa, embora não fosse imposta pela alta direção, se mostrou como principal meio de comunicação entre os níveis operacional e intermediário. De acordo com o relato do líder de produção (E01): “Às vezes até quando querem muito dar uma opinião, eles vêm a mim. Falam para mim, e eu repasso, não para os diretores, que eu também tenho uma barreira, mas, então, eu passo para o RH, e vai aos poucos, chegando até eles (E01)".

A partir dessas ações autônomas (ANDERSEN, 2004) e informais, foi possível identificar a forma emergente, na qual a geração de ideias emergiu para contribuir com a solução do problema. Essas ações ocorreram no sentido bottom-up, a partir da iniciativa de alguns indivíduos dos níveis hierárquicos inferiores (ANDERSEN, 2004; HAUTZ, 2017).

\subsubsection{EOE2.3: forma integradora}

A forma integradora pela qual ocorre o processo de open strategizing combina as duas formas anteriores, deliberada e emergente (ANDERSEN, 2004). Na Grafix, encontramos a integração entre essas formas por meio de planos e práticas, pela racionalização da decisão e ações autônomas, em um processo dinâmico, com ações ocorrendo no sentido middle-up-down, de forma articulada (MINTZBERG: WATER, 1985).

Assim, destacamos dois episódios que evidenciaram a aproximação com a forma integradora de open strategizing: (i) estabelecimento de política de preços e (ii) lançamento de e-book.

(i) Política de preços - redução da margem de lucros e do preço de venda. Assim como a ação de vendas, a organização, por meio dos principais líderes, percebeu que para atrair clientes e realizar contratos precisava ter preços atrativos em um mercado cada vez mais retraído, o que significava rever sua política de preços. Foi possível identificar, na reunião da direção, que a empresa estava disposta a reduzir sua margem de lucros para que o preço dos produtos e serviços fosse mais atraente e seduzisse os consumidores, evidenciado pelo relato 
da analista comercial (E03):

A gente entrou com uma ação para trabalhar com custo mais baixo para chamar
atenção dos clientes nesse momento, né? Que pagando um pouco menos depois dessa
crise ele já poderia estar com material pronto e até, de repente, vender por um valor
mais baixo, alguma coisa mais de lucro, porque o que a gente tinha antes ficou um
pouco parado agora (E03).

Ficou evidente a necessidade de alteração de política de preços também no relato do líder de produção (E01): "Daí baixou a margem de lucro dos atendimentos, das vendas, baixando um pouquinho de cada lugar para tentar manter, assim, até estabilizar de novo, eu acredito que até melhorar".

Percebemos que o estabelecimento de uma nova política de vendas caracterizou uma forma articulada do processo ocorrer; foi combinada entre os diferentes níveis de comando e operação devido à necessidade de mudança, que exigiu uma postura ativa e que envolvesse todos os participantes, desde a coordenação determinada pela alta direção até o envolvimento da equipe técnica.

(ii) Lançamento de e-book - uma ação de marketing positivo. Sabendo que o ambiente externo havia impactado fortemente nas atividades da organização, um grupo de funcionários teve a ideia de lançar, em uma parceria com uma escritora e ilustradora, um $e$ book infantil sobre o COVID-19. Já era de conhecimento da funcionária responsável pela editoração na Grafix a situação desta escritora e ilustradora que tinha interesse em publicar um e-book direcionado ao público infantil explicando o que era a atual pandemia, mas que não dispunha de recursos financeiros para levar o projeto adiante.

Em conversa com a gerente da empresa, o projeto de parceria na confecção do $e$-book foi aprovada e apresentada para os diretores como sendo uma ação de marketing positivo para os diretores. Nesse momento a empresa se disponibilizou a encontrar outros parceiros para revisão, diagramação e conversão do livro para forma digital a fim de realizar o lançamento.

A empresa arcou com boa parte dos custos de produção e publicação do material, e não possui indicadores que permitam medir o alcance e retorno desta ação. Porém, para os envolvidos, além do aprendizado, a ação sinalizou a necessidade de a empresa investir mais em ações de marketing e nas redes sociais.

Portanto, além dessas duas ações pontuais, os episódios já descritos que caracterizam a forma deliberada e a forma emergente pela qual o processo de open strategizing ocorre são também necessárias para compor e evidenciar a forma integradora que ocorre na Grafix. Esta forma de abertura da estratégia ocorre a partir de um processo que integra as decisões deliberadas e emergentes, equalizadas durante o processo de formação da estratégia. Podemos 
identificar nesse processo, de um lado, a racionalidade, centralização e hierarquia e, do outro, a maior participação e inclusão dos atores organizacionais, ajustados na busca para atender as demandas contingenciais (ANDERSEN, 2004; LAVARDA et al., 2010; CARDOSO; LAVARDA, 2015).

\subsection{ECE3: INCERTEZA PERCEBIDA PELA TURBULÊNCIA DO AMBIENTE}

Para tentar conter a pandemia, uma série de regras de isolamento foram determinadas em forma de decretos governamentais, afetando diretamente o ambiente organizacional. Em Santa Catarina, as empresas foram impactadas pelo primeiro decreto de emergência que determinou que as indústrias operassem em sua capacidade mínima necessária, em regiões de contaminação comunitária do COVID-19, seguido do decreto que definiu novas regras para as indústrias, como a redução mínima de $50 \%$ da força de trabalho para continuidade da operação e a adoção de medidas preventivas (SES, 2020).

Essa situação de turbulência do ambiente externo é composta por fatores complexos e dinâmicos provocando a incerteza na tomada de decisão (DUNCAN, 1972; MINTZBERG; AHLSTRAND; LAMPEL, 2010). Neste sentido, para podermos identificar a percepção da incerteza pelos gestores em relação à turbulência do ambiente externo, passamos a descrever os elementos operacionais deste estudo: complexidade e dinamismo do ambiente.

\subsubsection{EOE3.1: complexidade}

Segundo a Teoria da Contingência, a performance econômica das empresas é altamente afetada pela sua estrutura organizacional, pela tecnologia e pelo ambiente externo. A complexidade situa-se em algum ponto de um continuиm entre o simples e o complexo, e pode ser alterado de acordo com o nível de conhecimento da organização, necessário para enfrentar situações desconhecidas (MINTZBERG; AHLSTRAND; LAMPEL, 2010).

Nas entrevistas percebemos a complexidade do ambiente refletida nas preocupações da equipe. Um dos entrevistados (E02) destacou o quanto foi difícil enxergar o todo da situação da pandemia e, então, tentar entender o que estava por vir.

O ambiente no qual a Grafix está inserida, em situação normal, não é de alta complexidade, principalmente, pela experiência adquirida ao longo da história de atuação, o que, como apontam Mintzberg, Ahlstrand e Lampel (2010), pode reduzir a complexidade do ambiente. Com a pandemia, no entanto, e, especialmente, nos primeiros momentos (mês de 
março), a complexidade do ambiente parece ter aumentado em um nível que paralisou qualquer ação deliberada.

Importante notar que a responsabilidade por deliberar, na empresa, é atribuída aos diretores, mas, ao mesmo tempo, os entrevistados entendem a complexidade da situação e, quando questionados sobre o que teriam feito diferente, não sabiam o que propor, a não ser "uma comunicação mais frequente" (E02).

Para a analista de RH (E02) a situação de complexidade se deu porque foi "tudo muito rápido" e não permitiu prever o que aconteceria: "Acho que até todo mundo aceitar o que estava acontecendo, até todo mundo entender, acho que foi um pouquinho custoso ali no começo [...]. Porque a gente foi muito imediatista, a gente não conseguiu ver na frente".

As pressões resultantes das complexidades do ambiente externo, como, por exemplo, o elevado número de informações desconexas e sem comprovações de veracidade, geradas e repassadas, convergindo muitas vezes para notícias falsas, são difíceis de serem processadas e assimiladas internamente; o processamento dessa informação necessita que o conhecimento seja aprimorado (JARZABKOWSKI; FENTON, 2006).

A complexidade do ambiente provoca incerteza pela falta de conhecimento para fazer frente à nova situação, de experiência e de decisões prévias. Como este tipo de pandemia não tem precedentes, as ações se configuram em um desafio permanente com resultados inesperados.

\subsubsection{EOE3.2: dinamismo}

O dinamismo do ambiente em que uma organização está inserida pode ser identificado ao se observar a variação desse ambiente ao longo do tempo, considerando todas as mudanças decorrentes que, em alguma medida, impactam na capacidade de tomada de decisão da organização (DUNCAN, 1972).

Nas entrevistas, nas observações feitas e nos documentos facilitados pela Grafix (comunicados e cartazes disponibilizados no mural da empresa sobre o COVID-19, e os relatórios de produção dos meses de março e abril de 2020), percebemos os efeitos das mudanças ambientais repentinas, tornando o ambiente altamente incerto e dinâmico, gerando uma paralisia inicial.

Por meio dos relatos percebemos uma preocupação imediatamente posterior ao anúncio da pandemia e da quarentena. Vários questionamentos surgiram, em relação ao trabalho, como por exemplo: como vai ficar o mercado de impressões, que já vinha sendo ameaçado pelas (c) (1) @ REAd | Porto Alegre - Vol. 27 - N.․․ 1 - Janeiro / Abril 2021 - p. 1-34. 
tecnologias digitais? O mercado em que a empresa se encontra já sentia a ameaça da inovação tecnológica há algum tempo, e agora, em função do novo dinamismo, fica a questão sobre uma aceleração da adoção das novas tecnologias.

O que ficou evidente foi que um ambiente mais dinâmico parece exigir mais abertura para a participação dos indivíduos na busca pela solução dos problemas. A líder de produção (E01) destacou, por exemplo, o aumento da necessidade de comunicação para entender as mudanças de cenário e projetar novas ações: "Então, em relação a isso não estou tão insegura, eu fico mais insegura a longo prazo para outras questões, tipo virtualmente, como é que fica o segmento de livros?".

O dinamismo do ambiente acelerou o processo de mudança, demandando novas formas de trabalho (home office, por exemplo), adaptação das pessoas e organizações para atender às necessidades dos clientes. A empresa não estava preparada para essa situação, e as questões a serem respondidas ficaram expostas. No entanto, abriu espaço para a participação, embora o processo de mudança continuasse em evolução e as respostas ainda não fossem definitivas.

\section{MODELO TEÓRICO-CONCEITUAL}

Considerando a questão de pesquisa sobre como ocorre o processo de open strategizing frente à incerteza percebida pela turbulência do ambiente causada pela pandemia do COVID19, e buscando compreender este fenômeno ainda em evolução, entendemos que a ameaça e a incerteza causadas pela turbulência do ambiente influenciaram na atuação dos gestores em relação à forma como conduziram a tomada de decisão e, consequentemente, a forma como ocorreu a abertura da estratégia ou open strategizing.

Efetivamente, o processo de open strategizing ocorreu, em parte, de forma deliberada, se forem considerados as regulamentações e os decretos governamentais aos quais a organização teve que se adequar. Independentemente da compreensão da equipe diretiva sobre a situação em curso, o que veio em forma de legislação foi repassado e precisou ser cumprido, sendo essa deliberação imediata e sem espaço para participação (ANDERSEN, 2004; MINTZBERG; AHLSTRAND; LAMPEL, 2010).

A incerteza parece condicionar a abertura da estratégia (DUNCAN, 1972). Se a abertura da estratégia de forma proposital e deliberada é um desafio, diante da necessidade das circunstâncias se torna uma ação inevitável.

A partir da triangulação dos dados coletados nas entrevistas, podemos evidenciar que as principais decisões já haviam sido predefinidas. Percebemos que a preocupação com a saúde (c) (1) $\Theta$ REAd | Porto Alegre - Vol. 27 - N. 1 - Janeiro / Abril 2021 - p. 1-34. 
financeira da empresa, e, consequentemente, do próprio emprego, foi um tema central para cada colaborador nesse momento, que pareciam concordar que era necessário colocar o problema na mesa e debatê-lo.

No entanto, também houve contribuição da forma emergente no processo de open strategizing. Encontramos na Grafix um clima organizacional de muita tensão e preocupação decorrente dos riscos de contágio pela doença e também pelas demissões que estavam ocorrendo, e isso motivou a busca por alternativas e soluções práticas. A incerteza percebida do ambiente (PRIGOGINE, 1996) suscitou, indiretamente, uma abertura bottom-up.

O clima hostil, portanto, pode ter contribuído para aumentar a transparência da informação e a inclusão das pessoas de forma emergente. De modo geral, por estarem no "modo sobrevivência", as pessoas não questionavam e apenas reagiam à situação, fator que propiciou o surgimento de movimentos espontâneos que podem ter alterado o sentido do fluxo de informações para bottom-up. A forma emergente de open strategizing surgiu da necessidade de os funcionários levarem informações relevantes, que a alta direção não tinha como ter acesso por serem de natureza "da prática" e relacionada com as experiências profissionais e pessoais dos funcionários, para auxiliar a embasar as decisões gerenciais.

Os elementos que materializaram este processo são antagônicos (considerando as recomendações de isolamento social), pois possuem em sua lógica a propriedade de aglomeração, visto que ocorreram por meio de reuniões informais, briefings, brainstormings, etc., presenciais e que se tornaram mais frequentes e necessários para superar os problemas gerados pela pandemia. Não notamos, nas entrevistas e nas observações, nenhuma sugestão ou movimentação de realização de trabalho virtual ou home office por parte da equipe administrativa, por exemplo.

Desta forma, entendemos que o processo de open strategizing ocorreu de forma integradora, e foram encontradas evidências nas narrativas que corroboram esta afirmação. No começo da pandemia, os entrevistados sentiram a falta de debates, mas, ao analisarem a situação em retrospectiva, entenderam a relativa demora nas decisões e ações, pois ninguém sabia exatamente como agir, o que fazer ou o que propor, e essa incerteza gerou o debate. Percebemos, desta forma, que práticas de estratégia aberta aconteceram em decorrência das contingências: pessoas foram inseridas e a transparência da informação, se não totalmente adotada, foi exigida.

É difícil dimensionar a redução da incerteza em decorrência da abertura da estratégia, dado que a incerteza gerada pela pandemia, por exemplo, é um evento externo que está fora do controle da organização. No entanto, a abertura da estratégia proporcionou novas formas de 
lidar com a situação externa, inserindo mais pessoas no debate e promovendo a transparência das decisões e ações.

Podem parecer um paradoxo a abertura da estratégia e a incerteza percebida, pois, quanto maior a abertura, mais incertezas se percebem; são novas incertezas que precisam ser comunicadas para que se tenha uma capacidade maior de interpretação e de tomada de decisão. As incertezas precisam ser compartilhadas, pois o fato de estarem apenas na pauta da diretoria não resolve o problema e, ainda, como consequência, podem aumentar a distância percebida entre os níveis hierárquicos (JARZABKOWSKI et al., 2019).

A partir dessas considerações, desenvolvemos uma estrutura para ilustrar que o processo de open strategizing ocorre de forma integradora, com movimentos ascendentes e descendentes entre os elementos da forma deliberada e emergente. As decisões no sentido top-down são mais racionais e impostas, possuem em sua lógica maior centralização, hierarquização e controles. A forma emergente de abertura da estratégia possui maior ênfase nas ações e decisões coletivas, comportamentos criativos e foco no aprendizado, e sua lógica valoriza a inclusão das pessoas, transparência da informação e ações autônomas, ocorrendo no sentido bottom-up. Ambos os sentidos ocorrem simultaneamente durante o processo, no entanto, com a incerteza percebida decorrente na turbulência do ambiente (causada pela pandemia do COVID-19, neste caso), entendemos que o processo de open strategizing é facilitado; e as decisões, portanto, ocorrem no sentido middle-up-down, integrando pessoas, estrutura e estratégia nas relações de maneira não linear ou estruturada (Figura 1). 
Figura 1. Processo de Open Strategizing

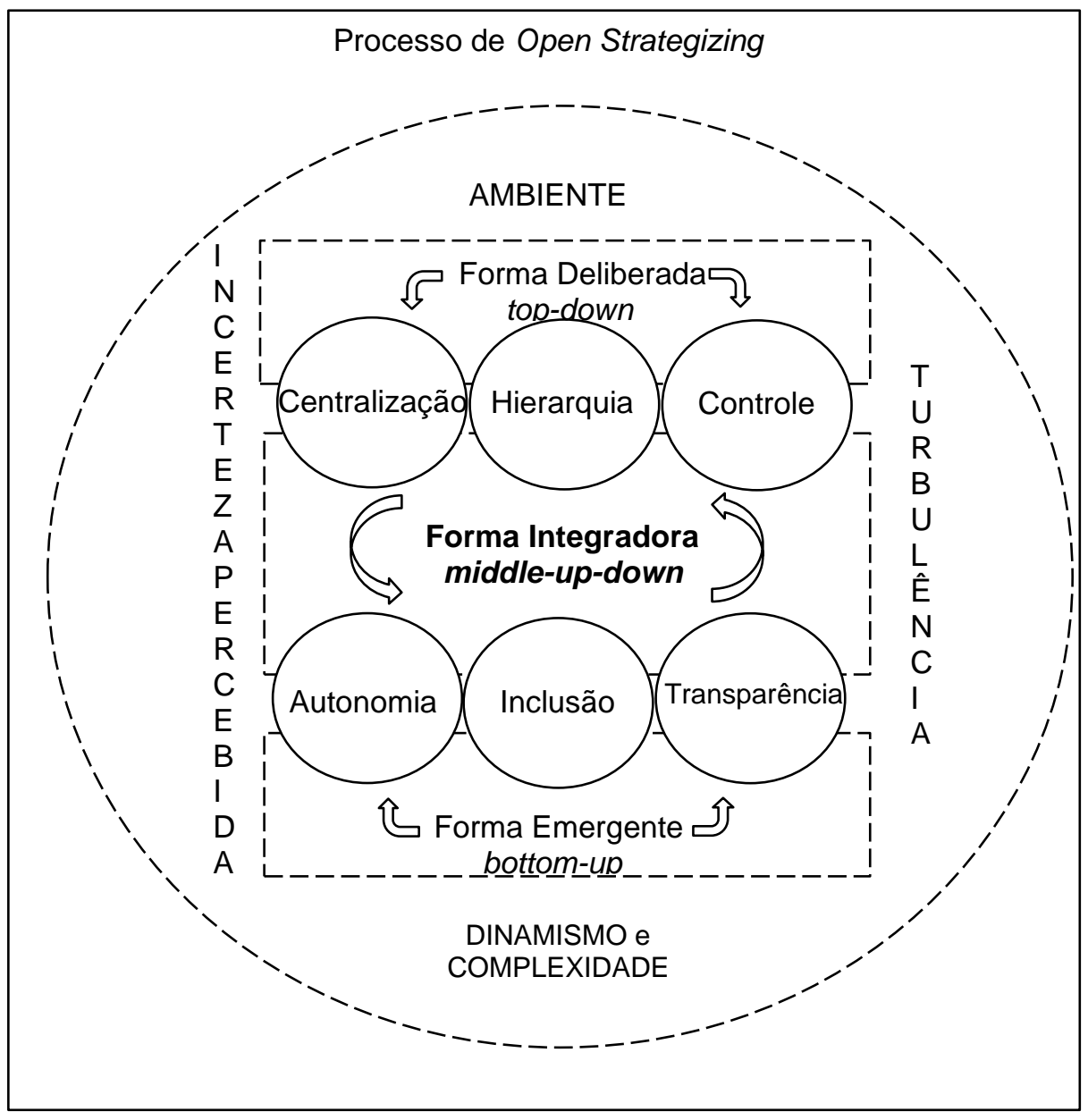

Fonte: Elaboração própria

De forma geral, percebemos que tempos difíceis e de alta incerteza parecem exigir ainda mais inclusão das pessoas e transparência das informações nas organizações. O contexto foi determinante para aumentar a incerteza e exigir nova postura, refletindo alta complexidade pelo desconhecimento da situação de pandemia, exaltando as individualidades e a hostilidade das relações, tanto em nível macro quanto micro-organizacional, e colocando a tecnologia como um fator que deve moldar novas formas de trabalho. Um fato esperado que altera completamente o fazer estratégico.

A partir da abordagem de open strategizing, e pelas considerações referentes a incertezas causadas pela turbulência do ambiente em que estamos inseridos, nos questionamos sobre alguns aspectos: como o planejamento de nossas ações é alterado em situações de crise? Ou, continuamos adotando as mesmas práticas, indiferentes ao contexto, ao "novo normal" que se anuncia? O que nos inquieta é que os processos e práticas da estratégia já não estejam respondendo de forma adequada à anormalidade. Quando respondem, parece ser de forma 
reativa, obedecendo à legislação emergente ou "apagando incêndios" da rotina operacional.

\section{CONSIDERAÇÕES FINAIS}

O objetivo desta pesquisa foi compreender como ocorre o processo de open strategizing frente à incerteza percebida pela turbulência do ambiente causada pela pandemia do COVID19. A partir do estudo de caso realizado em uma organização que presta serviço não essencial e que seguiu as recomendações dos decretos governamentais, foram encontradas práticas adotadas e identificados desafios enfrentados no momento em que o fenômeno se desenvolveu em larga escala, a nível mundial.

Embora a pandemia esteja em plena evolução enquanto esta pesquisa é concluída, com incertezas ainda predominando no contexto global, nacional e local, foi possível identificar que o processo de abertura da estratégia é um fenômeno que se intensifica e precisa de ajustes ao enfrentar essas incertezas percebidas no ambiente. A forma como ocorre a abertura da estratégia depende dos fatores ambientais e da decisão da direção. Como explicitaram Mintzberg e Waters (1985), o processo não é tão somente deliberado ou emergente, visto que a forma deliberada de abertura possui maior centralização, hierarquização e controle em relação à tomada de decisão; e, no outro extremo, a forma emergente possui maior ênfase nas ações e decisões coletivas, comportamentos criativos e foco no aprendizado (DOBUSCH; DOBUSCH, 2019).

A contribuição teórica desta pesquisa está na interação entre os elementos que compõem a perspectiva de open strategizing com a abordagem processual da estratégia e a teoria contingencial. A concatenação das bases teóricas utilizadas para a compreensão do fenômeno, bem como a atualidade do debate no qual se inserem, gera uma contribuição positiva. Ressaltamos a ideia de que um ambiente de incerteza extrema, de dimensão mundial (pois não se trata apenas de pressão ambiental do tipo tecnológico, concorrência, mudança de hábitos do consumidor), parece levar a gestão a priorizar as estratégias emergentes bem como ampliar práticas de inclusão de pessoas e transparência das informações no processo de tomada de decisão.

Duncan (1972) não abordou este tipo de ambiente em crise (grand challenge, para JARZABKOWSKI et al., 2019); a pandemia parece que criou uma nova dimensão de contingência ambiental que vai além do simples/complexo e estático/dinâmico, usados para caracterizar mercados nas condições normais de ambiente estável. Embora esse não tenha sido nosso enfoque, acreditamos que a abertura da estratégia aqui caracterizada não poderia se enquadrar nem mesmo nas tipologias clássicas de Miles e Snow (1978) para diferentes 
condições ambientais: defensiva, prospectora, analítica e reativa.

Nesse sentido, estamos tratando de uma relação contingência vs. estratégia que ainda não havia sido considerada pela literatura, nem poderia ser. Entendemos que esta reflexão pode gerar um pequeno avanço do conhecimento, que se justifica por pequenas contribuições que estimulam permanentemente a realização de novas pesquisas de interesse das organizações.

Como contribuição prática, destacamos a importância das práticas realizadas por uma organização em um ambiente de turbulência, em situação de crise e sem perspectivas de resolução a curto prazo. Pela vivência em tempo real da possibilidade de abertura da estratégia para o enfrentamento da crise causada pela disseminação do COVID-19, explicitamos como um fenômeno mundial afeta instantaneamente as práticas diárias de uma organização e apontamos como existem alternativas quando essa estratégia ocorre de forma aberta, articulando a inclusão das pessoas e a transparência da informação de forma integradora.

A limitação deste estudo está na percepção dos respondentes em relação aos questionamentos e à interpretação por parte da equipe de condução da pesquisa. A triangulação dos dados foi a alternativa metodológica adotada para redução deste possível viés de pesquisa.

Este estudo ficou limitado em relação a compreender como os diretores da empresa perceberam as ações dos fornecedores, as demandas dos clientes, as regulações e políticas governamentais e econômicas, as atividades dos concorrentes, as tecnologias disponíveis e em desenvolvimento para o setor gráfico, os novos produtos concorrentes (videolivros, lives, videoconferências, outros), o desenvolvimento de mercados de matéria-prima e a oferta de mão de obra, que continuam a causar incertezas em a partir desta pandemia.

Futuras pesquisas podem dar continuidade a este estudo, aprofundando essas questões limitantes, assim como investigar essa nova e complexa situação apresentada no ambiente externo, buscando saber como promover o equilíbrio entre open strategizing e o grau de controle das operações necessário frente às adaptações às condições da pandemia e depois dela.

Por fim, no intuito de ilustrar a realidade deste momento, encerramos nossa pesquisa com a citação da analista de recursos humanos, E03, da Grafix: "Essa incerteza de saber como vai ser o outro dia, acho que é o pior disso tudo". A situação de instabilidade que se descortina nos deixa com inúmeros questionamentos, possibilidades de pesquisa e, o mais importante, a convicção da necessidade de mudança de atitude em relação ao contexto.

A incerteza em relação ao futuro favorece a turbulência do ambiente, o que gera mais incertezas; desafiando as organizações, que precisam se reestruturar, se preparar e atuar com novas práticas para responder a essas incertezas e turbulência, dada a complexidade da situação. A open strategizing parece ser uma postura organizacional necessária para a prática da (c) $($ (1) $\Theta$ REAd | Porto Alegre - Vol. 27 - N.․ 1 - Janeiro / Abril 2021 - p. 1-34. 
estratégia em um ambiente em constante mudança e caracterizado por essa incerteza.

\section{REFERÊNCIAS}

ABDALLA, M. M.; CONEJERO, M. A.; OLIVEIRA, M. A. Administração estratégica: da teoria à prática no Brasil. São Paulo: Atlas, 2019.

ALMUTAIRI, A. N. M. The effect of using brainstorming strategy in developing creative problem solving skills among male students in kuwait: a field study on saud al-kharji school in kuwait city. Journal of Education and Practice, v. 6, n. 3, p. 136-145, 2015.

ANDERSEN, T. J. Strategic planning, autonomous actions and corporate performance. Long Range Planning, v. 33, n. 2, p. 184-200, 2000.

ANDERSEN, T. J. Integrating decentralized strategy making and strategic planning processes in dynamic environments. Journal of Management Studies, v. 41, n. 8, p. 1271-1299, 2004.

BURGELMAN, R. A. et al. Strategy processes and practices: dialogues and intersections. Strategic Management Journal, v. 39, n. 3, p. 531-558, 2018.

BURNS, T.; STALKER, G. M. The management of innovation. London: Tavistock, 1961.

BURRELL, G.; MORGAN, G. Sociological paradigms and organizational analysis. London: I-Ieinemann, 1979.

CARDOSO, F. E.; LAVARDA, R. B. Perspectiva da estratégia-como-prática e o processo de formação da estratégia articulada pela média gerência. REAd-Revista Eletrônica de Administração, v. 21, n. 3, p. 719-751, 2015.

CRESWELL, J. W.; POTH, C. N. Qualitative inquiry and research design: choosing among five approaches. Sage, 2016.

DOBUSCH, L.; DOBUSCH, L. The Relation between Openness and Closure in Open Strategy: Programmatic and Constitutive Approaches to Openness. In: SEIDL, D.; KROGH, G. von; WHITTINGTON, R. (Eds.). The Cambridge Handbook of Open Strategy. Cambridge: Cambridge University Press, 2019.

DONALDSON, L. The contingency theory of organizations. Sage, 2001.

DUNCAN, R. B. Characteristics of organizational environments and perceived environmental uncertainty. Administrative Science Quarterly, p. 313-327, 1972.

GIOIA, D. A.; PITRE, E. Multiparadigm perspectives on theory building. The Academy of Management Review, v. 15, n. 4, p. 584-602, 1990.

FARACO, M. M., LAVARDA, R. A. B., \& GELBCKE, F. L. Tomada de decisão em hospitais de ensino: entre formalismo e síntese intuitiva. Revista de Administração Pública, v.53, n. 4, p. 769$779,2019$. 
HAUTZ, J. Opening up the strategy process-a network perspective. Management Decision, v. 55, n. 9, p. 1956-1983, 2017.

HAUTZ, J.; SEIDL, D.; WHITTINGTON, R. Open strategy: dimensions, dilemmas, dynamics. Long Range Planning, v. 50, n. 3, p. 298-309, 2017.

INTERNATIONAL MONETARY FUND. World economic outlook: the great lockdown. Washington, 2020. Disponível em: https://static.poder360.com.br/2020/04/FMI-worldeconomic-outlook.pdf. Acesso em: 28 maio 2020.

IASBECH, P.; LAVARDA, R. A. B. Strategy and Practices: A Qualitative Study of a Brazilian Public Healthcare System of Telemedicine. International Journal of Public Sector Management, v.31, n.3, p. 347-71, 2018.

JARZABKOWSKI, P.; BALOGUN, J.; SEIDL, D. Strategizing: the challenges of a practice perspective. Human Relations, v. 60, n. 1, p. 5-27, 2007.

JARZABKOWSKI, P.; FENTON, E. Strategizing and organizing in pluralistic contexts. Long Range Planning, v. 39, n. 6, p. 631-648, 2006.

JARZABKOWSKI, P. et al. Exploring inter-organizational paradoxes: methodological lessons from a study of a grand challenge. Strategic Organization, v. 17, n. 1, p. 120-132, 2019.

KERLINGER, F. N. Metodologia da pesquisa em ciências sociais: um tratamento conceitual. São Paulo: EPU/EDUSP, 1979.

LAVARDA, R. B.; CANET-GINER, M. T.; PERIS-BONET, F. J. How Middle Managers Contribute to Strategy Formation Process: Connection of Strategy Processes and Strategy Practices. Revista de Administração de Empresas (RAE), v.50, n.4, p.358-370, 2010.

LAWRENCE, Paul R.; LORSCH, Jay W. Organization and Environment. Boston: Harvard Business School, 1967.

LIEBLICH, A.; TUVAL-MASHIACH, R.; ZILBER, T. Narrative research: reading, analysis, and interpretation. Sage, 1998.

MACK, D. Z.; SZULANSKI, G. Opening up: how centralization affects participation and inclusion in strategy making. Long Range Planning, v. 50, n. 3, p. 385-396, 2017.

MACKAY, R. B.; CHIA, R.; NAIR, A. Strategy-in-practices: a process philosophical approach to understanding strategy emergence and organizational outcomes. Human Relations. FORTHCOMING, 2020.

MILES, R. E.; SNOW, C. C. Organizational strategy, structure and process. New York: McGrow-Hill, 1978.

MINISTÉRIO DA SAÚDE. Painel Coronavírus. Brasília, 2020. Disponível em: https://covid.saude.gov.br/. Acesso em: 30 maio 2020. 
MINTZBERG, H.; AHLSTRAND, B.; LAMPEL, J. Safári de estratégia: um roteiro pela selva do planejamento estratégico. 2. ed. Porto Alegre: Bookman, 2010.

MINTZBERG, H.; WATERS, J. A. Of strategies, deliberate and emergent. Strategic Management Journal, v. 6, n. 3, p. 257-272, 1985.

MUNICÍPIO DE TUBARÃO. Decreto nº 4.989, de 19 de março de 2020. Tubarão, 2020. Disponível em:

https://static.fecam.net.br/uploads/681/arquivos/1739929_Decreto_de_Emergencia_COVID_ 19.pdf. Acesso em: 28 maio 2020.

PATON, B.; DORST, K. Briefing and reframing: a situated practice. Design Studies, v. 32, n. 6, p. 573-587, 2011.

PRIGOGINE, I. The end of certainty: time, chaos and the new laws of nature. New York: Free Press, 1996.

SEBRAE. Classificação por número de empregados. São Paulo, 2013. Disponível em: https://m.sebrae.com.br/Sebrae/Portal\%20Sebrae/UFs/SP/Pesquisas/MPE_conceito_empregad os.pdf. Acesso em: 16 jun. 2020.

SECRETARIA DE ESTADO DA SAÚDE. Coronavírus. Florianópolis, 2020. Disponível em: http://www.saude.sc.gov.br/coronavirus/. Acesso em: 16 jun. 2020.

SEIDL, D.; GUÉRARD, S. Meetings and workshops as strategy practices. In: GOLSORKHI, D. et al. Cambridge handbook of strategy as practice. Cambridge: Cambridge University Press, 2015.

SPEE, A. P.; JARZABKOWSKI, P. Strategic planning as communicative process.

Organization Studies, v. 32, n. 9, p. 1217-1245, 2011.

TAVAKOLI, A.; SCHLAGWEIN, D.; SCHODER, D. Open Strategy: literature review, reanalysis of cases and conceptualization as a practice. Journal of Strategic Information System, v. 26, n. 3, p. 163-184, 2017.

TROCHIM, W. M. K. Outcome pattern matching and program theory. Evaluation and Program Planning, v. 12, n. 4, p. 355-366, 1989.

WHITTINGTON, R. Strategy as practice. Long Range Planning, v. 29, n. 5, p. 731-735, 1996.

WHITTINGTON, R. Completing the practice turn in strategy research. Organization Studies, v. 27, n. 5, p. 613-634, 2006.

WHITTINGTON, R. Opening strategy: professional strategists and practice change, 1960 to today. New York: Oxford University Press, 2019.

WHITTINGTON, R.; CAILLUET, L.; YAKIS-DOUGLAS, B. Opening strategy: evolution of a precarious profession. British Journal of Management, v. 22, n. 3, p. 531-544, 2011. 
WORLD HEALTH ORGANIZATION. Coronavirus disease (COVID-19): situation report - 128. Geneva, 2020. Disponível em: https://www.who.int/docs/defaultsource/coronaviruse/situation-reports/20200527-covid-19-sitrep128.pdf?sfvrsn=11720c0a_2\&ua=1. Acesso em: 28 maio 2020.

YIN, Robert K. Case Study Research and applications: design and methods. 6. ed. California: Sage, 2018. 